\title{
Teoria e filosofia da comunicação
}

\section{RESUMO}

Primeiramente, este artigo traça o perfil da comunicação como um «campo de estudos de suporte prático» na cultura e sociedade contemporâneas. Em seguida traça as origens dos conceitos-chave da teoria da comunicação nas «tradições intelectuais» desde a Grécia clássica, passando por fontes modernas de «disciplinas científicas humanísticas e sociais», assim como por pesquisas interdisciplinares. Essas fontes forneceram diversos modelos de "processos comunicativos», que, por sua vez, influenciaram diferentes abordagens de "processos de pesquisa».

Palavras-chave: teoria da comunicação, dupla hermenêutica, tradições intelectuais, conceitos interdisciplinares, pesquisa em comunicação

\begin{abstract}
This essay first outlines the profile of communication as a scholarly field with a practical stake in contemporary culture and society. The following traces the origins of key concepts of communication theory in intellectual traditions since classical Greece, and in modern sources within humanistic and social scientific disciplines as well as interdisciplinary research. These sources have been fed selectively into various models of the process of communication, which, in turn, have informed different approaches to the process of research.
\end{abstract}

Key words: communication theory, double hermeneutics, intellectual traditions, interdisciplinary concepts, communication research

\footnotetext{
* Professor na Universidade de Copenhagen (Dinamarca).
} 
A TEORIA DA COMUNICAÇÃo possui raízes clássicas na história das idéias. Se a filosofia tradicionalmente debate a produção do conhecimento humano da realidade, a teoria da comunicação dedica-se à mídia, modalidades e mensagens em que humanos trocam, refletem e ordenam diferentes perspectivas dessa realidade. Revisando certas questões epistemológicas, éticas e políticas, enquanto responde à crescente influência da informação e tecnologias da comunicação na sociedade e na cultura no século XX, a pesquisa em comunicação desenvolve-se nos cruzamentos da filosofia social e teoria científica.

A comunicação se estabeleceu como uma categoria particular da atividade humana a partir do desenvolvimento da mídia eletrônica durante a última metade do século XIX. Esse desenvolvimento encorajou pesquisadores e outros comentadores a pensar sobre as diversas práticas de interação social - face a face, através de fios, pelo ar - em termos de sua familiaridade. Na formulação oportuna de Peters (1999: 6), "a comunicação de massa se antecipou”, concedendo atenção especial e explícita às variantes da comunicação em pesquisas, assim como na sociedade como um todo. Até a invenção do telégrafo, "o transporte e a comunicação eram inseparáveis" (Carey, 1989: 15), uma vez que qualquer ato comunicativo dependia da presença física de bardos, manuscritos, livros, jornais, ou outra mídia impressa. Com as telecomunicações nasceram diferentes maneiras de interagir no tempo e no espaço. Já com as tecnologias digitais, cada vez mais presentes no cotidiano e na organização diária, chegaram novos meios de informação e comunicação, cujas implicações sociais provaram ser mais radicais que a imprensa e o telégrafo, mais uma vez exigindo que as pesquisas em comunicação revisassem os seus conceitos fundadores.

Primeiramente, este artigo traça o perfil da comunicação como um «campo de estudos» de suporte prático na cultura e sociedade contemporâneas. As seções seguintes traçam as origens dos conceitos-chave da teoria da comunicação nas «tradições intelectuais» desde a Grécia clássica, passando por fontes modernas de «disciplinas» científicas humanísticas e sociais, assim como por pesquisas interdisciplinares. Essas forneceram diversos modelos de «processos comunicativos», que, por sua vez, influenciaram as diferentes abordagens de «processos de pesquisa».

\section{A DUPLA HERMENÊUTICA DA PESQUISA EM COMUNICAÇÃO} Como perspectivas da realidade, podemos dizer que todos os campos acadêmicos são comprometidos com a hermenêutica, interpretando o mundo a partir de pontos de vista específicos. Melhor dizendo, a pesquisa em comunicação pertence àquelas esferas acadêmicas comprometidas com a hermenêutica «dupla», interpretando as interpretações ou compreensões que as pessoas têm sobre 
como e por que elas se comunicam e restituindo essas interpretações de segunda ordem às pessoas em questão e à sociedade como um todo. Comparadas às ciências naturais e físicas, as ciências sociais e humanas estudam realidades pré-interpretadas. Nas palavras do antropólogo Cliford Geertz (1983: 58), grande parte das pesquisas em comunicação e cultura humana procuram determinar "do que os humanos são capazes".

A noção de hermenêutica dupla é familiar desde as primeiras teorias culturais e sociais; podemos citar, por exemplo, a abordagem de Max Weber para compreender (Verstehen) os sentidos subjetivos como uma maneira de descrever (Erklären) eventos socialmente objetivos. A terminologia específica da dupla hermenêutica foi desenvolvida por Giddens (1979), que se baseou nos questionamentos de Winch (1963) às concepções científico-naturais predominantes nas ciências sociais pós-1945. Por um lado, as ciências sociais encontram um mundo pré-interpretado em forma de afirmações, comportamentos e documentos fornecidos pelos atores sociais. Por outro, as intervenções e interpretações apresentadas pelas pesquisas sociais e culturais não podem deixar de fazer a diferença nos domínios estudados - desde reconsiderações respondentes, ainda que inapropriadas, de opiniões em pesquisas políticas, a reconcepções maiores, por exemplo, da natureza das transações econômicas ou da psicologia individual, instigadas pela disseminação dos trabalhos de Marx e Freud.

A pesquisa em comunicação pode ser considerada dupla hermenêutica por três diferentes razões. Primeiramente, os estudos em comunicação se voltam para processos básicos em que a realidade social é interpretada e reinterpretada no cotidiano, na conversa diária e nas instituições especializadas, das escolas às novas mídias. Segundo, como um campo, a pesquisa em comunicação tem sido, a partir da articulação do século XIX de uma categoria denominada «comunicação", uma reação ao crescimento de um setor social de instituições dedicadas à informação e comunicação, as quais Beniger (1986) se refere como revolução do controle, que foi concluída no final dos anos 30 na alvorada da pesquisa moderna em comunicação. Das burocracias governamentais às pesquisas de mercado e a «mídia de massa», esse setor produz informações que permitem planejamento, coordenação e controle de âmbito social. Terceiro, as rápidas transformações das práticas comunicativas na sociedade do século XX e o vantajoso sucesso das tradições de pesquisas individuais que os explicam, levaram o campo a se tornar cada vez mais interdisciplinar, observando a comunicação por meio de diferentes perspectivas das ciências humanas, sociais e, em certo grau, das ciências naturais. Assim, a dupla hermenêutica da pesquisa em comunicação se desdobra simultaneamente no interior do campo acadêmico e em seu vínculo com o campo empírico de estudo. 
A noção de dupla hermenêutica pode ser concretizada na referência à formulação de McQuail (2005) sobre os cinco tipos de «teoria». A «teoria científica»é a concepção mais comum do termo, abrangendo conceitos explanatórios gerais e modelos aplicáveis a uma grande variedade de instâncias empíricas, associadas especialmente às tradições sócio-científicas (e naturais científicas) de pesquisa quantitativa. A «teoria cultural» é um legado das artes e das humanidades, valendo-se de abordagens textuais e outras abordagens qualitativas, que têm contribuído significativamente para a pesquisa interdisciplinar contemporânea. A «teoria normativa» dedica-se a resultados legítimos e meios de organização de recursos da comunicação, especialmente a mídia de massa, da impressa à Internet. Enquanto a pesquisa em comunicação desenvolve-se na interface da filosofia social e da teoria científica, as teorias normativas também se desenvolvem como uma área isolada das atividades de pesquisa, particularmente considerando a imprensa, sustentando-se no planejamento e debate público. A «teoria operacional» é o domínio dos profissionais da mídia e outros comunicadores e comunicólogos, representando as regras práticas e o conhecimento tácito, assim como as posições éticas e ideológicas a respeito da finalidade e status de seu trabalho. Dessa forma, a teoria operacional constitui tanto um objeto de pesquisa empírica, no caso de estudos de jornalistas e professores de comunicação, como também uma fonte de compreensão teórica em processos comunicacionais. Por fim, a «teoria do cotidiano» trata de interações individuais entre cidadãos, consumidores, fontes de informação e a mídia. Praticamente todos possuem uma noção de como a comunicação opera, e aos interesses de quem.

Um denominador comum para os cinco tipos de teoria é que eles permitem às pessoas agirem - como estudiosos, reguladores, profissionais e usuários da comunicação. O que caracteriza o estudioso da comunicação é o seu potencial para auto-reflexividade sistemática e sustentada em conclusões e ações fundamentadas. A pesquisa em comunicação considera teorias científicas normativas, operacionais, cotidianas e as outras teorias citadas; ela restitui teorias reconsideradas. Como em outros campos acadêmicos, a pesquisa em comunicação equivale a uma instituição pensante (Douglas, 1987), efetuando uma dupla hermenêutica contínua acerca das instituições e práticas contemporâneas de comunicação. Sendo assim, o campo foi constituído por uma grande variedade de tradições na história das idéias, e de disciplinas na pesquisa universitária moderna.

\section{TRADIÇÕES INTELECTUAIS ATRAVÉS DOS SÉCULOS}

Sem dúvida, o mais antigo conjunto de idéias de grande influência nas teorias da comunicação vem da tradição retórica. Para Aristóteles, a retórica era fonte de um tipo particular de conhecimento provável e razoável, enquanto a lógica 
geraria um conhecimento exato ou "necessário" (Clarke, 1990: 13). O legado da retórica, então, é o reconhecimento da íntima relação entre saber qual é a circunstância e saber como comunicar sobre ela. O que sabemos, como indivíduos ou comunidades, depende crucialmente das capacidades mentais e dos recursos materiais disponíveis para articular tal conhecimento. Como a produção de conhecimento na ciência, a produção de significados na comunicação pode ser relacionada à ênfase relativa tanto nas entidades carregadas de insight intelectual quanto nos processos que resultam em tal insight. Essa distinção - entre o significado como "produto" pré-definido ou "processo» participativo - pode ser remontada em várias teorias da comunicação posteriores, descritas por James Carey (1989) como modelos rituais e de transmissão de comunicação.

A retórica se constituiu a partir de recursos e convenções de tradições orais antigas, ainda que a retórica "clássica» tenha sido codificada e consolidada como uma parte de uma transição para a cultura literária (Havelock, 1963). Além disso, o ponto de partida da retórica era a fala, especialmente em relação à realidade, e como argumentar sobre ela. Em comparação, a «hermenêutica» se desenvolveu fora de uma prática de leitura e compreensão de textos escritos ou narrativos. Considerando os textos originalmente pertencentes aos campos da religião e do direito, particularmente textos do início do século XIX em diante, os princípios e procedimentos da hermenêutica foram aplicados às artes e a outros tipos de textos - sem dúvida, à experiência humana como tal. Não somente a Bíblia e os clássicos, mas as sociedades modernas e subculturas prestam-se às análises hermenêuticas. Uma contribuição da hermenêutica do século XX foi o que Paul Ricoeur identificou nos trabalhos de Marx, Niestzsche e Freud, e mais tarde desenvolveu como «hermenêutica da suspeita» (Ricoeur, 1981: 46). Seu propósito era descobrir princípios velados nos discursos e ações de pessoas e instituições sociais, expondo interesses e motivações que para elas podem estar igualmente veladas. Essa leitura nas entrelinhas da sociedade com propósitos reformatórios e terapêuticos tem sido de interesse central dos estudos críticos em comunicação.

Desde a poética clássica na tradicional história da arte até o modelo moderno, a «estética» sempre permaneceu como uma fonte de inspiração para o exame sistemático de como as expressões e experiências significativas ocorrem na comunicação humana. Além dos domínios isolados de descrença e contemplação desinteressada, a estética também serve para explicar como as formas específicas de representação relacionam-se com as funções do mundo real das mídias. Podemos dizer que a teoria estética recente re-enfatiza uma compreensão das artes como fenômenos materialmente fundamentados e práticas socialmente situadas (e.g., Summers, 2003). No caso das formas midiáticas 
digitais e interativas, a estética tem se voltado ao estilo e tem sido abordada por estudiosos e profissionais para justificar a reelaboração da mídia e dos gêneros familiares nas novas formas de representação e interação.

As humanidades modernas tomaram forma por volta do início do século XIX como uma configuração inclusiva das tradições eruditas, incorporando a retórica, a hermenêutica, a estética e outras abordagens para o estudo da história, da cultura e da comunicação (para uma visão geral, ver Jensen 2002b) - ainda que a noção de comunicação estivesse em formação naquele século (Peters, 1999). O contexto era a reconcepção das universidades como instituições produtoras de conhecimento por meio da "pesquisa», associadas à tradição humboldtiana na Alemanha (Fallon, 1980; Rudy, 1984). Isso contrastava, nos domínios da história e da cultura, com concepções precipitadas de conhecimento como autoconsciência ou aprendizagem clássica, tal qual sancionada e administrada por uma categoria de eruditos (Kjorup, 2001: 20-22). Enfatizando procedimentos analíticos e estruturas conceituais para a pesquisa sobre cultura e consciência humana por meio de atenção detalhada às fontes históricas e outras fontes empíricas, as humanidades ajudaram a moldar as bases da pesquisa em comunicação moderna.

Se o início do século XIX foi marcado pela institucionalização das humanidades como uma das correntes que mais tarde influenciaram as pesquisas em comunicação, no século XX presenciamos uma predisposição da Academia a uma segunda corrente das ciências sociais (para uma visão geral, ver Murdock, 2002). Respondendo a uma realidade de intensas e velozes mudanças sociais, várias disciplinas científico-sociais surgiram a fim de efetuar uma dupla hermenêutica da economia, da política e da cultura. É possível dizer que, introduzidas no campo da pesquisa em comunicação, as diversas disciplinas científico-sociais e seus especialistas posicionam-se em um eixo - simultaneamente epistemológico e político - que oscila do consenso ao conflito. A comunicação é parte e parcela de um contínuo trabalho social de coordenação e confrontação, de processos micro-sociais a estruturas macro-sociais. Existe ainda um abismo nas conferências e publicações atuais entre as análises funcionais, de Spencer e Durkheim em diante, e a teoria crítica, de Marx, passando pela Escola de Frankfurt à «economia política da mídia, estudos feministas e de gêneros e teoria pós-colonial».

Esse duplo legado das ciências sociais para a pesquisa em comunicação tem se complexificado e enriquecido em diversos aspectos. O mais importante, talvez, é que as abordagens interpretativistas e construtivistas serviram como uma lembrança constante de que a conduta da vida social depende crucialmente dos recursos simbólicos disponíveis. A comunicação antecipa ações sociais e 
configura a estrutura social. A «interação simbólica», que surgiu da grande tradição filosófica do "pragmatismo», exerceu grande influência nos estudos sobre a contribuição da comunicação ao senso de comunidade e de individualidade. Além disso, nas ciências sociais e humanidades, a fenomenologia reafirma a compreensão de consciência como um todo vivido e interpretado. Embora a fenomenologia possa ser interpretada no contexto social como uma reação defensiva contra o reducionismo dos moldes positivista e psicologista, ela se torna um ingrediente ativo da teoria social do século XX e da «metodologia qualitativa». Um exemplo característico, que sugere perspectivas disciplinares e interdisciplinares distintas da comunicação como um objeto de análise, é a «psicologia em processos sociais», que tem sido abordado de várias maneiras como uma questão de interpretação ou medida, explicação ou desenvolvimento.

\section{CONCEPÇÕES INTERDISCIPLINARES ATRAVÉS DAS DÉCADAS}

O início do século XX marcou o surgimento de dois níveis de desenvolvimento no campo acadêmico que estimularam os estudos em comunicação pós-1945. Por um lado, as disciplinas acadêmicas especializadas se tornaram a ordem do dia, operacionalizando idéias intelectuais em conceitos explanatórios para a pesquisa empírica, enquanto cuidava das necessidades das profissões e burocracias na sociedade moderna. Considerando que a cultura nacional e a cultura acadêmica são diferentes (sobre o caso da Alemanha, ver Löblich, 2007), a autêntica e reconhecida história dos estudos em comunicação nos Estados Unidos (Dennis \& Wartella, 1996) é indicativa de uma visão abrangente de que a pesquisa em comunicação se sustenta de disciplinas científico-sociais específicas (para uma crítica ver Hardt, 1999). Embora Schramm (1997) descreva o seu desenvolvimento em referência aos seus «antepassados» (Lewin, Kurt; Lasswell, Harold D.; Lazarsfeld, Paul F.; Hovland, Carl I.), a substância conceitual e analítica é derivada de disciplinas impessoais (ciência política, sociologia, psicologia social e experimental).

É importante dizer que uma história similarmente parcial dos estudos da comunicação poderia ser contada sob a perspectiva das humanidades. Além das tradições históricas e intelectuais já notadas, os candidatos a fontes disciplinares incluem história da arte, teoria literária, lingüística e estudos fílmicos. É interessante notar que a segunda edição da obra amplamente divulgada de Lowery e DeFleur sobre o marco miliário (sócio-científico) da pesquisa em comunicação de massa faz referência a um crescente "paradigma do significado" (Lowery e DeFleur, 1988: 455), que poderia admitir um marco miliário humanístico. Apenas sete anos mais tarde, no entanto, na terceira edição, essa antecipação de uma possível convergência foi substituída por um retorno às 
múltiplas e paralelas "teorias centradas", cada uma explicando "conjuntos de eventos ou fenômenos de claras fronteiras" (Lowery e DeFleur, 1995: 397). O crédito de disciplinas relevantes e a definição de interdisciplinaridade permanecem, assim, contraditórios.

Por outro lado, a pesquisa em comunicação sempre foi tendenciosamente interdisciplinar. Isso é evidente, não somente em histórias do Partido Whig a respeito das origens interdisciplinares do campo, mas também em algumas das mais influentes contribuições a seus conceitos e técnicas analíticas. Ao menos duas dessas fontes podem ser identificadas. Primeiro, a «semiótica» e o «estruturalismo», em múltiplas variantes e em combinação a outras tradições de pesquisa, como por exemplo, a retórica e a hermenêutica, forneceram estruturas detalhadas e rigorosas para o estudo do que Ferdinand de Saussure chamou, há um século, de «a vida dos signos na sociedade». Desenvolvendo-se nos estudos da lógica e da linguagem do século XIX, essas tradições inspiraram muitos lingüistas e teóricos literários do período entre-guerras, e consolidaram-se em uma corrente de estudos midiáticos humanísticos dos anos 60, embora tenham mais tarde também influenciado a pesquisa sócio-científica sobre comunicação e cultura.

A segunda família de tradições interdisciplinares é mais comumente associada às ciências sociais e às concepções técnicas e sistemáticas da vida social. A cibernética, herdeira da engenharia e das ciências naturais, se tornou independente durante os anos 40 e 50 como uma ciência generalizada de controle da comunicação entre humanos e máquinas. A tradição semelhante da «teoria dos sistemas», tendo perdido seu sonho original de uma teoria de todos os sistemas, exerce hoje fraca influência. Enquanto isso, as teorias da «informação» como uma categoria lógica, estatística e algorítmica representavam a chave do projeto e do estudo das mídias de comunicação por todo o período pós-1945.

Apesar da familiaridade entre as categorias analíticas, por exemplo, da semiótica e da cibernética, qualquer convergência dessas e outras fontes interdisciplinares em alguma teoria consensual da comunicação não está em progresso e talvez nunca ocorra, e pode não ser vantajosa. Ao invés disso, a convergência entre as ciências humanas, sociais, e em certo nível, das ciências naturais e exatas pode ser vista como uma expressão de um ethos profissional e uma agenda de pesquisa, em que devem refletir um grau de maturidade disciplinar que leve em consideração a tolerância intelectual e a curiosidade. Pelo menos desde a questão do "crescimento do campo" do Journal of Communication (1983), tal posição tem avançado amplamente - ainda que a tolerância possa se tornar indiferença entre os nichos. Além disso, o processo pode tomar a forma de convergências locais, mas não uma convergência global no campo. Para trazer à baila outros casos de linhas de estudo incompatíveis, podemos citar 
os «estudos culturais» e as "ciências cognitivas» que, cada uma à sua maneira, integraram elementos de diversas disciplinas das humanidades e ciências sociais. Elas constituem interdisciplinas por si mesmos e componentes de outras disciplinas e campos existentes, incluindo a pesquisa em comunicação. Ao passo que os estudos culturais trouxeram a hermenêutica clássica e outras estratégias analítico-discursivas bastante difundidas na sociedade moderna, investigando suas entrelinhas e fissuras, as ciências cognitivas revisitaram tardiamente a noção de inteligência artificial, desenvolvida anteriormente pela neurociência e pela antropologia.

O propósito da teoria da comunicação, assim, não deve ser a construção de uma estrutura interdisciplinar a partir de blocos disciplinares, mas esboçar um plano de como estruturas múltiplas poderiam ser construídas e reconstruídas. A afirmação de Craig (1999) sobre a teoria da comunicação como uma prática metadiscursiva é bastante sugestiva: a teoria da comunicação é constituída em e por meio de atos comunicativos que se voltam a problemas práticos e questões de comunicação no mundo real, e que desenvolve soluções e reflexões diversas e concorrentes. A meta-perspectiva de Craig sobre o campo revelou sete tradições da teoria da comunicação: retórica, semiótica, fenomenologia, cibernética, psicologia social, teoria sociocultural e teoria crítica. Enquanto suas definições e delimitações permanecem contestáveis, esse é precisamente o ponto de um meta-modelo constitutivo: a teoria da comunicação é uma prática comunicativa, e se desenvolve na relação com outras práticas e contextos comunicativos.

São essas práticas que podem ser vistas, mais geralmente, como instâncias dos estudos da «dupla hermenêutica». A pesquisa em comunicação é inter, trans e multidisciplinar e tradicional; é tudo isso em resposta a uma realidade que se comunica infinitamente - ou o tenta fazer. A infra-estrutura das instituições de pesquisa, jornais e conferências oferece evidências ainda mais antigas dessa dialética. Além das distinções disciplinares e sistemáticas, tais como «comunicação e a lei, economia midiática, produção e conteúdo midiático e efeitos midiáticos», o campo tem sido organizado de acordo com os domínios da relevância prática, por exemplo, da «comunicação educacional»e da "comunicação estratégica», e com vistas a noções contraditórias, tais como «comunicação popular». Novas configurações institucionais de uma herança teórica surgem; identidades disciplinares revisadas com uma posição direta sobre comunicação emergem, como no caso das ciências da informação (que em alguns cenários costumam ser conhecidos como biblioteconomia), cujas questões de pesquisa, com a digitalização, sobrepõem crescentemente as «interações homem-máquina». E, devido à centralidade da mídia e da comunicação na sociedade contemporânea, as pesquisas em comunicação são freqüentemente 
questionadas em público a prestar contas sobre papel da comunicação nas transformações sociais; podemos citar, por exemplo, a referência a uma possível era de pós-modernismo e comunicação. As respostas efetuam, assim, uma dupla hermenêutica na comunicação viva.

\section{O PROCESSO DE COMUNICAÇÃO}

Em relação às divergências disciplinares e intelectuais, a maioria das formas de pesquisa em comunicação compartilha ao menos uma compreensão em comum dos processos de comunicação. Diversos «modelos de comunicação» têm sido empregados desde os primórdios do campo como representações simplificadas, mas heuristicamente úteis, do domínio de estudo. Os termos «emissor-receptor, mensagem e canal» podem ser considerados relativamente unânimes, especialmente se considerarmos a reversibilidade dos papéis e o feedback. No entanto, no que se refere ao «contexto» dessa interação, as abordagens das ciências humanas e sociais tendem à concordância. Considerando que o cientista social ideal e típico caracterizado por Lasswell (1948) considerará os contextos em termos de ambiente natural e cultural embutidos na comunicação e sendo representados por ela, o seu contraponto humanístico jakobsoniano (Jakobson, 1960) considerará literalmente contextos como textos, como sendo sempre estruturas discursivas. E, embora esses dois modelos clássicos de comunicação possuam mais do que uma semelhança superficial, eles envolvem epistemologias alternativas. No paradigma de Lasswell, os comunicadores são indivíduos ou instituições reais que dizem algo intencionalmente por meio de um canal físico a alguém, induzindo certos comportamentos; no modelo jakobsoniano, comunicadores equivalem a funções imanentes ou traços em um texto. Esse recente foco nos veículos discursivos da comunicação é reenfatizado pela categoria de "código», tal como a língua e cinematografia inglesa, que complementa o canal físico (denominado por Jakobson de «contato») - no paradigma de Lasswell, os códigos não são elementos essenciais. Um terceiro modelo fundamental, que possui origem na engenharia, mas é amplamente aplicado às ciências da comunicação, refere-se a qualquer coisa que se esteja transmitindo por meio de algum canal de comunicação como uma «mensagem», comunicação essa que pode ser mal-sucedida devido a um «ruído» (Shannon e Weaver, 1949). Em resumo, o «conteúdo» significativo do processo comunicativo pode ser definido tanto positivamente, como seleções e combinações no interior de um código de expressão, quanto negativamente, referindo-se àquela porção da mensagem que não sofre interferência de um ruído no canal de transmissão - assim como em termos indiretos das intenções e comportamentos dos emissores e dos receptores. 
A tradicional fronteira entre as abordagens das ciências humanas e sociais para o processo comunicativo pode ser traçada em duas concepções distintas de comunicação: como um modo de «representação» ou um «meio» de ação. Por um lado, as humanidades enfatizam as formas simbólicas por meio do qual os humanos re(a)presentam diferentes aspectos da realidade como parte de um processo intersubjetivo de cognição e reflexão. As teorias destacam a representação como uma "expressão» cognitiva e estética, como uma forma externa de «troca, e como uma fonte internalizável de «experiência». Por outro, as ciências sociais dão prioridade à comunicação como um meio de interação social coordenada, ou como um tipo de interação por si mesmo, desenvolvendo todas as formas de práticas sociais, culturais e psicológicas.

Devido o seu foco em formas de representação na comunicação, as humanidades têm gerado um legado fértil de conceitos a respeito dos veículos de comunicação. Primeiro, os textos foram compreendidos, desde os anos 60, como portadores de cultura, incluindo tanto a mídia impressa quanto a audiovisual, ilustrações e artefatos do cotidiano. Os conceitos de «textualidade» e «intertextualidade», derivados da teoria literária do século XX, sugerem que não-textos são ilhas - textos que adentram em redes de configurações históricas ancestrais e contemporâneas. Muito antes dos hipertextos e da world wide web, as ciências humanas reconheceram a interconectividade dos textos como nós da comunicação e da cultura.

Segundo, o discurso refere-se ao uso da língua e de outros signos em contextos sociais, às vezes instantâneos concretos de um texto particular (e.g., um espetáculo de Hamlet). O discurso, assim, desloca a atenção de entidades textuais para os processos localizados em que a comunicação se desdobra. Em um sentido mais amplo, o discurso se refere ao uso de signos que articulam e testemunham visões de mundo, ideologias e formações culturais próprias. Os discursos multiplicam-se na cultura por meio da comunicação. E também, de acordo com as «teorias de cultivo» como compreendidas pelos estudos midiáticos, a comunicação cultiva humanos, para melhor ou para pior, por meio das mídias historicamente disponíveis.

Nas tipologias dos veículos de comunicação, as humanidades freqüentemente concedem atenção especial ao gênero como um nível intermediário de análise de textos ou discursos específicos e suas estruturas institucionais e midiáticas. Enquanto a teoria literária tradicionalmente examina gêneros épicos, líricos e dramáticos e suas variantes culturais e históricas, os estudos da comunicação e da mídia se dedicam a uma grande variedade de gêneros (e subgêneros), muito além da «ficção» - gêneros que incluem o noticiário e as séries televisivas, email e jogos de online, disputas amorosas e diálogos paciente- 
terapeuta. Os gêneros são equivalentes textuais de uma grande variedade de práticas sociais, no público e no privado, ambientes online e offline, como explorado, por exemplo, na «comunicação organizacional» (e.g., Yates e Orlikowski, 1992) e no "contexto da comunicação mediada por computadores".

Apesar das diferentes concepções de "conteúdo» da comunicação, as ciências sociais e humanas concordam sobre o conceito performativo de «significado» ou o conceito contextual de «informação». As humanidades cada vez mais prestam contas ao sentido representacional em termos de sua contribuição para a contínua estruturação da cultura e da sociedade (Giddens, 1984); as ciências sociais, igualmente, tratam a informação como «uma diferença que faz a diferença» nas interpretações assim como nas ações em contextos sociais e culturais. A comunicação também pode ser definida como práticas de «interação» humana que dependem da «interatividade», não somente na nova mídia digital, mas também em toda a variedade de «mídias» e «modalidades» «programáveis» - é através de um conjunto de combinações extremamente complexas de materiais e recursos simbólicos disponíveis da comunicação que as representações humanas da realidade e as interações iterativas na e com essa realidade se tornam possíveis. A comunicação permite dúvidas e adiamentos - paradas, reflexões e representações antes de cada ação.

A convergência de conceitos sobre «mídia»e «comunicação», como já indicado, foi facilitada pelas novas formas e contextos midiáticos de comunicação, que demandam pesquisas interdisciplinares. $\mathrm{O}$ ambiente midiático contemporâneo foi moldado pela «intermidialidade» em um sentido tecnológico, estético e institucional. Nesse processo, a nova mídia confia e molda os repertórios da mídia antiga. Algumas das questões para a nova pesquisa interdisciplinar são: como as diversas práticas diárias de comunicação se relacionam com «a mídia» como instituições específicas dedicadas à comunicação sobre outras instituições na sociedade - políticas, econômicas e culturais? Quais são os propósitos e fronteiras dos diferentes processos de comunicação? E quais deveriam ser os propósitos e estruturas institucionais dos diferentes tipos de pesquisa em comunicação?

\section{O PROCESSO DE PESQUISA}

O processo de pesquisa pode ser visto como um caso especial no processo de comunicação, ainda que certamente seja contestável, como observou Craig (1999: 155, nota 10), já que é muito questionada a afirmação de que a pesquisa em comunicação é "a disciplina fundamental que explica todas as outras disciplinas, [todas as quais] que são constituídas simbolicamente por meio da comunicação". A pesquisa em comunicação é um tipo específico de prática comunicativa com propósitos e interesses sociais particulares. A concepção de "interesse 
no conhecimento" - explanatório, interpretativo ou emancipatório - sugere que os propósitos e interesses não são externos, mas aspectos constitutivos da ciência e da erudição. A distinção entre a pesquisa "administrativa" e "crítica" (Lazarsfeld, 1941) é baseada em premissas teóricas e procedimentos de pesquisa, e não em preferências políticas.

Apesar da diversidade de abordagens de pesquisa que se inserem no campo da pesquisa em comunicação, é possível identificar certas posições prototípicas, fundamentadas em diferentes formas de inferência. No cenário acadêmico, duas auto-concepções de pesquisadores do que eles acham que eles são capazes (Geertz, 1983: 58) são freqüentemente colocadas em oposição umas às outras - raciocínio hipotético-dedutivo apoiado pelas metodologias quantitativas, e raciocínio abdutivo baseadas na metodologia qualitativa. (De fato, provavelmente grande parte dos estudos em comunicação, falando de maneira geral, baseia-se na indução - pesquisas do tipo descritivo, comercial e/ou confidencial que sustentam estratégias comerciais e planejamento público). Essas posturas adotadas nas pesquisas acadêmicas em comunicação estão ligadas às grandes tradições da epistemologia e da teoria da ciência, que historicamente representam culturas distintas de pesquisa (Snow, 1964), apesar das várias propostas de reintegração (Brockman, 1995). De um lado, o «racionalismo crítico» desenvolve uma grande parte das pesquisas empíricas em comunicação, particularmente estudos quantitativos. Isso apesar do fato de que a pesquisa prática nem sempre corresponde às expectativas dos critérios estipulados por Popper, considerando a pesquisa em comunicação como um todo, como outros campos e disciplinas, e ainda assim ela continua a debater as definições e implicações da «objetividade nas ciências». De outro, o «construtivismo» exerce grande influência, especialmente nos estudos críticos, qualitativos e interpretativos em comunicação. Em suas versões mais radicais, podemos dizer que o construtivismo abandona uma noção moderna de erudição como representações intersubjetivamente validadas da realidade que as coletividades sociais produziriam, preferindo a narrativa ao argumento.

Recapitulando, as duas abordagens prototípicas da pesquisa em comunicação podem ser relacionadas a diferentes aspectos ou níveis de estudos empíricos (Figura 1). Debates envolvendo a dicotomia qualitativo-quantitativo geralmente se concentram nesses níveis individuais, referindo-se especialmente aos níveis de coleta e análise de dados. É importante dizer que, no entanto, é o projeto ou «metodologia» de pesquisa, e não a teoria, que distingue as pesquisas quantitativas e qualitativas - embora as metodologias façam parte de um conjunto de estruturas teóricas e técnicas analíticas. As similaridades e diferenças entre essas duas correntes são provavelmente melhor compreendidas se notarmos 
como elas associam - ou separam - os diversos níveis de análise. Os estudos quantitativos em comunicação tendem a assumir que a separação dos momentos de conceitualização, projeto, compilação e análise de dados e interpretação é tanto possível quanto desejável. Já a pesquisa qualitativa defende que ao menos certos fenômenos comunicativos requerem um processo de pesquisa que se mova de forma livre em todos os níveis analíticos a fim de articular e diferenciar as categorias analíticas, para que análises detalhadas sejam parte constitutiva do processo. São essas diferenças que, sobretudo, justificam a resistência entre duas correntes, que resumem as grandes dicotomias conceituais na história da ciência moderna - idiográfico vs nomotético, verstehen vs erklären, êmica vs ética.

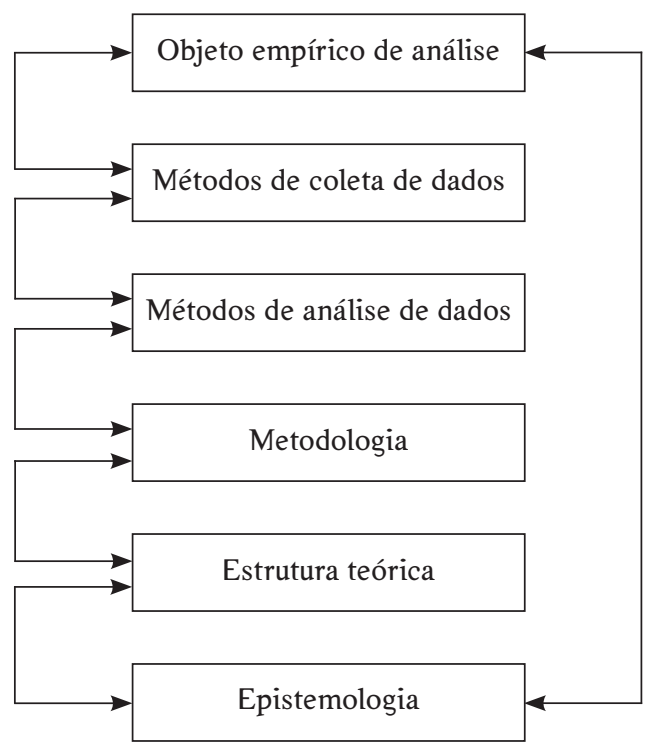

F I G U R A 1. Seis níveis da pesquisa empírica

A pesquisa em mídia e comunicação atual vem passando por um processo de convergência entre as tradições intelectuais e disciplinares desde os anos 80, explorando a complementaridade das versões científico-sociais qualitativa e quantitativa, humanística e social do processo de pesquisa. Se definido negativamente, o campo é pré-paradigmático, carente de um conjunto consensual de premissas metodológicas, epistemológicas e ontológicas (Kuhn, 1970). Mas, se definido positivamente, o campo representa um lugar de diálogo entre, em um sentido frágil, «paradigmas» no plural. Uma vez que o processo é aberto, a evidência de publicações e conferências sugere que essa convergência pode desenvolver-se, e até poderia ser consolidado em estruturas epistemológicas e meta-teóricas que reconhecem o valor explanatório da pesquisa qualitativa e quantitativa; podemos citar, por exemplo, o realismo científico (Jensen, 2002a; Pavitt, 1999).

Em cada turno da pesquisa dialógica, a teoria e a filosofia da comunicação, no sentido de uma epistemologia que implica compromisso ontológico e político, são imprescindíveis. Na Figura 1, o nível epistemológico retroage sobre os objetos empíricos de análise, assumindo definições e justificativas prévias do que constituem objetos relevantes de análise, e do que representam métodos analíticos admissíveis, permitindo inferências para além daqueles objetos. Algumas 
instituições de pesquisa internacionais em comunicação tendem a tratar a teoria e a filosofia como interesses distintos e temas desligados do núcleo das atividades de pesquisa. A título de exemplo, a Filosofia da Divisão da Associação de Comunicação Internacional foi formada em 1985 em torno de "elementos gêmeos: a teorização da comunicação e a politização da filosofia" (Erni, 2005: 374). Na prática, a divisão representa "um lar para os estudos filosóficos, críticos e culturais" (Erni, 2005: 371), questionando explícita e implicitamente premissas teóricas e metodológicas em outras seções dessa associação. Um de seus dilemas era como estabelecer um nicho para reflexão teórica sem torná-lo um nicho para teorias particulares, repelindo uma hegemonia científica sobre seus «outros» no diálogo. Certamente, são necessárias duas partes para se comunicar, assim como reflexividade em ambas as partes para alcançar um diálogo. Um desafio importante para os futuros estudos em comunicação, nas divisões, nichos e tradições, é como acomodar e tratar a teoria e a filosofia da comunicação, não como práticas separadas ou auto-suficientes, mas como condições necessárias da pesquisa em comunicação como tal.

O esforço sobre as agendas de pesquisa, conceitos teóricos e procedimentos analíticos são, enfim, partes de uma dupla hermenêutica da pesquisa em comunicação. Os estudos em comunicação examinam a realidade contraditória das práticas comunicativas que os usuários e estudiosos da comunicação tanto se preocupam. Uma outra razão para teorizar a comunicação no início do século XXI é a sua transformação nas estruturas tecnológicas e institucionais. A mídia - livros, imprensa, rádio e teledifusão, a Internet -sempre serviu como fontes de reflexão e deliberação em uma escala macro-social, como instituições pensantes (Douglas, 1987); a digitalização afeta cada componente e processo dessas instituições - quem, o que e como da comunicação. A pesquisa em comunicação cumpre o papel de instituição pensante de segunda ordem, sem garantias de que suas descobertas e insights possam ser adotados nos estudos ou prática diária da comunicação. A comunicação dos estudos da comunicação é, assim, uma questão incerta e inacabada. $\mathbf{M}$ 


\section{REFERÊNCIAS}

BENIGER, J. (1986). The Control Revolution. Cambridge, MA: Harvard University Press.

BROCKMAN, J. (ed.) (1995). The Third Culture. New York: Simon and Schuster.

CAREY, J. (1989). Communication as Culture. Boston: Unwin Hyman.

CLARKE, D. S. (1990). Sources of Semiotic. Carbondale: Southern Illinois University Press.

CRAIG, R. T. (1999). Communication Theory as a Field. Communication Theory; 9(2): 119-161.

DENNiS, E. E. \& WARTElla, E. (eds.) (1996). American Communication Research: the Remembered History. Mahwah: Lawrence Erlbaum.

DOUGLAS, M. (1987). How Institutions Think. London: Routledge Kegan Paul.

ERNI, J. N. (2005). Does Philcomm Matter? Notes for an "Investigative Audience". Communication Review, 8: 371-375.

FALlON, D. (1980). The German University: A Heroic Ideal in Conflict with the Modern World. Boulder: Colorado Associated University Press.

GEERTZ, C. (1983). Local Knowledge. New York: Basic Books.

GIDDENS, A. (1979). Central Problems in Social Theory. London: Macmillan. . (1984). The Constitution of Society. Berkeley: University of California Press.

HARDT, H. (1999). Review of Dennis and Wartella. Communications: The European Journal of Communication Research, 24(2), 239-240.

HAVELOCK, E. A. (1963). Preface to Plato. Oxford: Blackwell.

JA KOBSON, R. (1960). Closing Statement: Linguistics and Poetics. In: Style in Language (T. A. Sebeok, ed.). Cambridge: MIT Press, pp. 350-377.

JENSEN, K. B. (2002a). The Complementarity of Qualitative and Quantitative Methodologies in Media and Communication Research. In: A Handbook of Media and Communication Research: Qualitative and Quantitative Methodologies (K. B. Jensen, ed.). London: Routledge, pp. 254-272. . (2002b). The Humanities in Media and Communication Research. In: K. B. Jensen (ed.), A Handbook of Media and Communication Research: Qualitative and Quantitative Methodologies. London: Routledge, pp. 15-39.

KENNEDY, G. A. (1980). Classical Rhetoric and its Christian and Secular Tradition from Ancient to Modern Times. Chapel Hill: University of North Carolina Press.

KJORUP, S. (2001). Humanities, Geisteswissenschaften, Sciences Humaines: Eine Einführung. Stuttgart: J. B. Metzler.

KUHN, T. S. (1970). The Structure of Scientific Revolutions. Chicago: University of Chicago Press.

LASSWELL, H. D. (1948). The Structure and Function of Communication in Society. In: The Communication of Ideas (L. Bryson, ed.). New York: Harper, pp. 32-51. 
LAZARSFELD, P. F. (1941). Remarks on Administrative and Critical Communications Research. Studies in Philosophy and Social Science, 9: 2-16.

LÖBLICH, M. (2007). German Publizistikwissenschaft and its shift from a humanistic to an empirical social scientific discipline: Elisabeth Noelle-Neumann, Emil Dovifat, and the Publizistik debate. European Journal of Communication, 22(1): 69-88.

LOWERY, S. A., \& DEFLEUR, M. L. (1988). Milestones in Mass Communication Research: Media Effects. $2^{\text {nd }}$ ed. New York: Longman.

. (1995). Milestones in Mass Communication Research: Media Effects. $3^{\text {rd }}$ ed. New York: Longman.

MCQUAIL, D. (2005). McQuail's Mass Communication Theory. $5^{\text {th }}$ ed. London: Sage.

MURDOCK, G. (2002). Media, Culture and Modern Times: Social Science Investigations. In: A Handbook of Media and Communication Research: Qualitative and Quantitative Methodologies (K. B. Jensen, ed.). London: Routledge, pp. 40-57.

PAVITT, C. (1999). The Third Way: Scientific Realism and Communication Theory. Communication Theory, 9(2): 162-188.

PETERS, J. D. (1999). Speaking into the Air: A History of the Idea of Communication. Chicago: University of Chicago Press.

RICOEUR, P. (1981). Hermeneutics and the Human Sciences: Essays on Language, Action and Interpretation. Cambridge: Cambridge University Press.

RUDY, W. (1984). The Universities of Europe 1100-1914: A History. London: Associated University Presses.

SCHRAMM, W. (1997). The Beginnings of Communication Study in America: A Personal Memoir. Thousand Oaks: Sage.

SHANNON, C. \& WEAVER, W. (1949). The Mathematical Theory of Communication. Urbana: University of Illinois Press.

SNOW, C. P. (1964). The Two Cultures and a Second Look. Cambridge: Cambridge University Press.

SUMMERS, D. (2003). Real Spaces: World Art History and the Rise of Western Modernism. London: Phaidon.

WINCH, P. (1963). The Idea of a Social Science. London: Routledge.

YATES, J., \& ORLIKOWSKI, W. (1992). Genres of Organizational Communication: A Structurational Approach to Studying Communication and Media. Academy of Management Review, 17(2): 299-326.

Traduzido por Mariane Murakami

Artigo recebido em 15 de setembro de 2008. 
